\title{
Alegoría y símbolo en el cine barroco y moderno. Estrategias retóricas, amplificación de sentido
}

\author{
Carlos Fernando Alvarado Duque \\ Misael Alejandro Peralta Rodríguez
}

Resumen: En este artículo se desea mostrar cómo la alegoría y el símbolo, en el marco del cine barroco y moderno, no son mecanismos ornamentales, sino una forma de invención semántica capaz de cuestionar la gramaticalización del lenguaje cinematográfico. No se busca hacer un análisis historiográfico de un determinado periodo del cine, sino mostrar que dichas figuras son capaces de producir sentido, sin negar su rol funcional, gracias a su uso poético. Através de un estudio de caso, de corte cualitativo (que se deriva de una investigación sobre Retórica del cine), se presenta una exegesis de sus dinámicas en cuatro filmes emblemáticos: El ciudadano Kane, Cantando bajo la lluvia, Deseo en una mañana de verano y Pierrot el loco (los dos primeras, barrocos; los dos segundos modernos).

Palabras clave: lenguaje fílmico; discurso retórico; cine barroco; cine moderno; símbolo; alegoría.

Abstract: Allegory and symbol in the baroque and modern cinema - Rhetorical strategies, amplification of meaning The scope of this paper is to show how allegory and symbol, in the framework of the baroque and modern cinema, are not ornamental mechanisms, but a form of semantic invention capable of questioning the grammaticalization of the cinematographic language. We don't intend to make a historiographic analysis of a certain period of the cinema, but to show how these figures are capable of producing meaning, without denying their functional role, thanks to their poetic use. Through a qualitative case study (derived from a research on film rhetoric) we present an exegesis of their dynamics in four emblematic films: Citizen Kane, Singing in the Rain, Wish on a Summer Morning and Pierrot the Madman (the first two, baroque; the second two: modern).

Keywords: film language; rhetorical discourse; baroque cinema; modern cinema; symbol; allegory. 
Nuestro interés es un acercamiento al funcionamiento de dos figuras retóricas (alegoría y símbolo) al interior del séptimo arte. Nos sumamos al esfuerzo de la neo-retórica por estudiar las maneras de producción de sentido en un amplio espectro de textos. En dicho horizonte, el lenguaje aparece en calidad de medio y objeto de estudio. Nuestras figuras reconfiguran las prácticas tradicionales del lenguaje y se decantan por la multiplicación del sentido. No realizamos una investigación histórica, únicamente utilizamos dos cortes (barroco y moderno) como escenarios para abordar el análisis. Metodológicamente operamos en términos de estudio de caso, desde un punto de vista cualitativo, con el examen de dos películas barrocas y dos películas modernas, seleccionadas a partir del reconocimiento de la crítica especializada.

Creemos que las figuras retóricas trabajan de manera consustancial con las estrategias de lectura que activa el espectador, por lo cual son también efecto de un ejercicio interpretativo. Operan en calidad de mirada, de acto de donación de sentido. En tal medida, es importante decir que en cualquier de los periodos es factible leer estas figuras (o incluso otras más). La pregunta que ha movido nuestra pesquisa indaga sobre el modo en que las figuras retóricas reconfiguran el lenguaje, crean otros modos de relación con lo real.

Presentes en el cine, las diversas figuras se apropian en la práctica hasta formalizarse. Esto puede generar una lexicalización que anula la capacidad de ampliar el sentido. Nos interesa, por eso, la alegoría y el símbolo que poseen una carga poética fuerte. Esperamos que este trabajo suponga una crítica a cualquier visión fonocéntrica, que considere que las figuras retóricas son privativas del universo lingüístico. El cine, extraño híbrido que roba a otras expresiones artísticas, también se ha visto tentado a crear una lengua, el sueño metafísico de un lenguaje de base. A la postre, el estudio de las figuras retóricas también le ha hecho el juego a la simple ornamentación.

\section{Pensar la alegoría}

En el universo de las figuras retóricas, la alegoría aparece vinculada, en un particular combate, con el símbolo. La distancia principal entre ambas, como bien sugiere Todorov (1991), reconstruyendo el pensamiento de Goethe, radica en la aparente naturalidad del símbolo (casi extensión intuitiva de las cosas) y la pura artificialidad de la alegoría (intervención tecno-racional sobre lo real).

La potencia de la alegoría radica en que se distancia de la idea del lenguaje como una suerte de metafísica de la realidad y supone una realidad que se reescribe. Su trabajo es un ciframiento del Afuera en clave especular. Si existiera algún mensaje, éste siempre depende del disfraz, no al contrario. Para Brea (2007), emerge como una ilustración. Optaremos, como bien expone Owens (2001), por una visión de la alegoría como palimpsesto (que tiene sobre sí el mecanismo del disfraz), como sistema de sobreescrituras que bien puede recorrer diversos estratos de nuestros modos de configurar el Afuera. 
La alegoría, pensada como una estrategia retórica que opera en el terreno del más puro artificio, proclama que no es naturaleza sino técnica desatada. De Man (1990) la amplifica hasta considerarla como una metafigura que domina todo modo de lectura através de la artificialidad. Como lo acota Brea (2007), con De Man, nos encontramos frente a una metatextualidad para una figura que no se agota en una sola lectura.

Si tenemos presente que todo signo no puede ser copia de un mundo natural, solamente falsificación, la alegoría es un artificio postergado, un doble de una falsificación. Se nos revela que, si la lectura es buscar un significado original, siempre estaremos condenados a la ruina. Benjamin (1989) comparte la idea de que la alegoría opera como lenguaje capaz de dar forma a nuestras relaciones con el Afuera ya que no es técnica sino expresión en imágenes. Siempre postergada, la alegoría presenta un mundo retrasado temporalmente. Un mundo en ruinas como pedazos de la ilusión metafísica de la naturaleza. No es una imagen que devela una naturaleza, es un fragmento que establece nexos en la pura superficie.

Esta figura se convierte en una estrategia en las prácticas artísticas contemporáneas que se distancian de cualquier forma clásica de representación. Burger (2000) concibe la dinámica de las vanguardias como el avance de obras inorgánicas. Contra un arte orgánico, la vanguardia opta por el trabajo sobre materiales que se resisten a ser articulados para dar paso a una totalidad natural. Por su parte, Owens (2001) señala que la alegoría se sintoniza con las prácticas artísticas que trabajan en términos de reciclaje textual. En calidad de mecanismo que genera variaciones escriturales, el valor de la alegoría estriba en la mutación de sus propios materiales para dar cuerpo a otros modos discursivos en el trabajo de las interrelaciones. En palabras del pensador, se convierte en un palimpsesto como paradigma.

Brea (2007) nos presenta una visión de nuestra figura que profundiza en el hecho de la mutación. Recupera la idea de que la alegoría opera como jeroglífico. De la convención secreta (el mensaje cifrado) únicamente accedemos a la expresión pública (el jeroglífico). Esta antinomia (convención/expresión) nos muestra que la alegoría opera en el terreno del lenguaje manteniendo activa sus fuerzas. Esta suerte de collage enfatiza la importancia de tomar distancia de la visión retórica clásica que circunscribe la alegoría al modelo del lenguaje figurado, con fines, en principio, ilustrativos.

\section{Pensar el símbolo}

Deseamos caracterizar el símbolo desde dos perspectivas: semiótica y hermenéutica. En los estudios semióticos se analiza su funcionamiento como una estructura. Peirce (1965), al clasificar el signo desde el punto de vista de su objeto (todo signo está compuesto por tres aristas: representamen, objeto e interpretante), sugiere tres tipos: ícono, índice y símbolo. En esta clasificación, el símbolo se define por una convención (pura arbitrariedad) que permite el vínculo (por demás artificial) entre el signo y lo que representa. 
El símbolo es fruto de un contrato social que selecciona una materia significante que no guarda relación alguna con el significado que debe vehicular. Diversos trabajos esbozan que, en la gran mayoría de casos, subyace una relación analógica que ha sido olvidada o queda encubierta (LE GUERN, 1990). Una de las virtudes del enfoque semiótico es la comprensión del símbolo a partir de cierta plasticidad, en relación con un contexto textual específico. Con ello, Lotman (1996) afirma que el símbolo arrastra sobre sí una dimensión extrasemiótica que le permite revelar cómo la significación no puede reducirse a estructuras.

Umberto Eco (1998) propone que ciertos rasgos en el plano expresivo (bajo ciertas circunstancias) dan paso al universo simbólico. Denomina a su perspectiva: modo simbólico. Supondría reconocer la confluencia de rasgos que hacen que x elemento dé paso a lo que comúnmente denominamos símbolo. No existen símbolos, sino lecturas simbolizantes. Trabajo semiótico que se completa en el plano exegético de los universos simbólicos.

Beuchot (2004) ofrece un acercamiento al símbolo bajo la idea de una hermenéutica analógica, lo cual implica pensar que todo ejercicio de interpretación tiene de base una relación connatural entre el objeto de sentido y sus formas de enunciación. Señala que es un signo que posee múltiples significados, por eso no se agota en la exégesis, siempre tiene un excedente que ninguna cultura puede suplir. Su visión del símbolo supone el encuentro entre dos fragmentos unidos por un signo. La manera de reconocer esta unión yace en un vínculo proporcionado por la analogía. Si bien supone la interpretación, apresa al símbolo en el mecanismo. El pensador nos recuerda que el símbolo supone una experiencia vital. No es simplemente un objeto para ser leído en clave conceptual, sino un tipo de presencia en la que el intérprete se instala. Es tanto de naturaleza cognitiva como emocional.

Panikkar (1994), por otra parte, brinda una perspectiva del símbolo que cuestiona el valor hermenéutico tradicional. Su punto de vista se distancia de cualquier modo de comprensión conceptual del símbolo. Todo intento de explicación intelectual destruye el símbolo, ya el mismo acto de pensar lo convierte en objeto. Cercano a la fenomenología, el símbolo es lo que da paso a la experiencia de vida. En términos de funcionamiento, este pensador nos sugiere que el símbolo tiene un carácter relacional. Su valor no estriba en las dos mitades que une, sino en el hecho de que la unión crea los dos fragmentos, crea la unidad, borrar la separación simbolizado-simbolizante. En este terreno, la tarea que resta a quien se acerca es la de dejar que el símbolo se despliegue.

Mardones (2003) asegura que el símbolo sabe esconder el misterio en medio de su lenguaje. Accesible a cualquier mortal, el universo yace para ser presenciado (en una buena pintura, una ópera, una película). Una suerte de destrucción de la gramática de los lenguajes informativos es Ilevada a cabo por la fuerza poiética del símbolo, mediado por el mito. Su centralidad radica en que, cuando estamos al borde del misterio, opta por mantener la tensión. Se penetra para amplificarlo, no para disolverlo. 


\section{Cine barroco}

Una de las marcas de identidad del barroco es el exceso. Se asocia con la sobrecarga de la forma que desea superar a la naturaleza. Calabrese (1989) enuncia el barroco como registro que da paso a la polidimensionalidad. Supone una línea que rompe el orden dado como natural. Su presencia siempre ejerce una alteración que puede pasar inadvertida en el marco de una experiencia mayor o aparecer en primer término gracias a una excesiva fragmentación.

El cine ha sido un territorio en el cual el barroquismo se hace presente. Para efectos de análisis tematizaremos el cine de las décadas del cuarenta y cincuenta como un cine de inclinación barroca. No sugerimos que todas las obras de este periodo puedan cobijarse con esta etiqueta. Pensamos que parte de ellas se acogen a la estrategia enunciativa del barroco que supone un sutil corte con el cine clásico. Nos acogemos, por lo menos teóricamente, a la relación consustancial propuesta entre esta estrategia discursiva (que desborda la retórica) y la inclinación por un tono barroco.

González Requena (2006) caracteriza el cine de Hollywood posterior al periodo clásico como manierista. Y si bien no pretende hacer uso del término barroco, decantarse por una descripción que excede los mecanismos de configuración de un modelo representativonaturalista, es una perfecta antesala al barroquismo. Indica que el trabajo de la cámara, encargada de la escritura en imágenes, cambia su punto de vista lo que da como resultado un sabotaje de la comprensión de los motivos de los personajes.

Casseti y Di Chio (1991) se centran en el mismo marco histórico de González, pero utilizan la categoría barroco como modelo de identidad. Los semiólogos italianos presentan tres regímenes para analizar sincrónicamente el funcionamiento de un filme. Entre ellos, el régimen de escritura incluye el barroquismo. Deciden denominar escritura barroca al estilo colectivo de los directores hollywoodenses de este particular periodo. Señalan que la escritura barroca se registra como una manifestación lingüístico-expresiva en la cual los extremismos y la marginalidad son la base de la escritura.

\section{El ciudadano Kane (1941)}

Quisiéramos sostener que el El ciudadano Kane, de Orson Welles, opera en clave barroca. Quizás, alcanza a convertirse en modelo del barroco al generar un sabotaje del clasicismo por exceso. Gracias al uso perfeccionista de técnicas de composición, el filme nos regala imágenes cuya construcción alcanza una fuerza expresiva tan alta que sabotea cualquier posible referente de base.

Esta obra nos ofrece, en un primer momento, una exégesis, gracias a la escritura barroca, capaz de centrifugar el Afuera en una muy concentrada expresividad. No dejamos de maravillarnos por la capacidad de introducir diversos matices que, del tamaño de los objetos, el manejo del claroscuro o la complejidad de formas, 
desemboca en encadenamientos que ofrecen una fluidez que borra la sutura que supone todo montaje. La segunda lectura, el ejercicio alegórico, aparece sobre este acto magistral de imitación. La maestría técnica hace lo que no se espera, revelar su existencia. Es tan poderoso su efecto que se hace evidente su toque. Cuando esto ocurre, se arruina el trabajo de ocultar el artificio. Son tan perfectas las imágenes que rompen la ilusión de realidad. Las contemplamos como cuadros, no podemos verlas como simple flujo visual.

Creemos que la historia alegoriza la imposibilidad de alcanzar a totalidad un propósito. El filme puede pensarse como un falso biopic que narra la vida de Charles Foster Kane. Tras la muerte de este megalómano, un periodista es encargado de investigar el significado de su última palabra pronunciada: Rosebud. Y podemos considerar que esta búsqueda, infructuosa, alegoriza la imposibilidad de alcanzar una meta que suponga revelar los secretos de una vida. Al igual que no es posible descifrar el significado de la misteriosa palabra, fracasa el intento de crear un mundo naturalizado en pantalla.

La ruina técnica de la naturaleza se revela virtualmente en todas las imágenes del filme. La secuencia inicial, que presenta a Xanadú (mansión del protagonista), ofrece un acercamiento desde las afueras de la residencia hasta la ventana del cuarto en que se encuentra Kane. Un puñado de planos permiten el ingreso, pero con una falsificación en las proporciones. Welles focaliza nuestra atención en la ventana. Cada plano cambia de punto de vista (genera una variación espacial). Sin embargo, la ventana se encuentra en el mismo lugar dentro del cuadro fílmico. El artificio radica en que, a pesar del acercamiento, el tamaño de la ventana no varía. Pareciera una marca de luz desterritorializada. El efecto es una continuidad que amplifica la naturalidad, la consecuencia alegórica es su artificialidad.

No es difícil pensar que el barroquismo de la distribución espacial del cuadro, como la predilección por un marcado uso del claroscuro, el uso de lentes (o de algunos objetos traslucidos) que deforman la imagen, termina revelando la factura del filme. Dos casos nos revelan la inclinación barroca que deviene en alegoría de la ruina. A manera de retrospectiva se narra el momento en que los padres de nuestro protagonista planean un mejor futuro para su hijo. La composición nos ofrece (como una representación dentro de la representación) una ventana que revela al pequeño chico jugando en la nieve con su trineo. Dos escenas en un mismo cuadro, un espacio plano que amplifica la realidad, ofrecen profundidad sin hacer uso de técnicas de composición que apelen a líneas de fuga. Si bien pareciera una imagen natural, virtualmente en cualquier lugar, la fuerza expresiva, el contraste entre la evidente felicidad infantil y la amarga decisión que toman los padres, el hogar como símbolo refugio, terminan por sabotear su intento de naturalidad. Alegóricamente se nos narra el choque de contrarios, se sabotea la simbólica del Afuera indómito y el adentro tranquilizador.

El segundo caso tiene lugar al final del filme. Kane ha muerto y está por concluir la investigación del periodista quien no sabe el sentido de la palabra Rosebud y acepta su derrota (los espectadores sí desciframos el misterio gracias a la imagen). Los bienes 
de su mansión yacen apilados en cajas. La cámara nos revela los restos de una vida. Y el espacio escénico se amplía conforme la cámara retrocede. La experiencia visual es tan excesiva que nuevamente se sabotea cualquier naturalidad. Las cajas devienen ataúdes del mundo material. Estos cadáveres objetuales, alegoría de la ruina, arruinan al final del filme, en un gesto propio de lo sublime, de cualquier clasicismo.

Cadáveres de estuco que alegorizan el sueño de inmortalidad. Al final, solo queda materia, en un barroco castillo vacío, cuyo misterio se des-hace precisamente porque no representan nada natural. Su potencia radica en que operan como alegoría de una vida truncada en sus más ambiciosos sueños, de un cine cuya perfección imitativa lo hace devenir una oda al trabajo tecno-material.

\section{Cantando bajo la lluvia (1952)}

Esta película, de Stanley Donell y Gene Kelly, es una alegoría del cine como escritura; lo es porque se dirige al mundo del cine que, con la excusa de una historia de amor, alegoriza las técnicas de inscripción del séptimo arte. El mundo filmográfico, en este caso el periodo de tránsito entre el cine silente y el sonoro, compone su dimensión diegética. Nuestro protagonista, una exitosa estrella del cine silente, tiene que enfrentar el paso a un nuevo registro estético donde la palabra adormece el cuerpo (cine concentrado en la phoné). Nuestra protagonista, dueña de una melodiosa voz, termina trabajando en Hollywood sin el reconocimiento merecido. Su amor se juega en la crítica a la banalidad del cine y la sobrevaloración del teatro. Personajes alegóricos dan cuerpo a la lucha entre formas artísticas, entre la imagen y la palabra. Al final este duelo alegorizado se resuelve en una particular oda al cuerpo. Visualidad y verbalidad se conjugan en la danza. El cuerpo habla, la voz opera por sus imágenes acústicas. Sobreescritura alegórica que recuerda el rebus que tanto interesó a Benjamin (1989) (caligrafía cinemática).

Estamos ante una comedia musical que apropia el fragmento como una de sus marcas estéticas. A diferencia de cierto uso de la fragmentación para dar pie al collage (marca propia de la vanguardia), su uso en este filme busca sugerir la sensación de organicidad (por eso el fragmento deviene detalle). No cabe duda que el ejercicio barroco supone, como en el cine clásico, que la película parezca una extensión de la vida. Gran parte de los acontecimientos tienen lugar en medio de los escenarios de Hollywood. Dichos espacios aparecen como fragmentos de un sistema. Esta alegoría del cine como sobreescritura termina por infectar la vida cotidiana de nuestros personajes.

El escenario es un estudio. Y a partir de utilería, y varios recursos técnicos, se simula la noche para dos amantes. $Y$ sabemos que, en ese escenario (que sugiere otro), se enamoran. Acertamos que esta historia imita al cine. Juego de alegorizar la vida como escritura en imágenes en movimiento, como un puro tejido de materias heterogéneas. Y la escena en que nuestro protagonista le cuenta a su mejor amigo sobre su historia de 
amor ocurre en un particular recorrido que tiene como fondo varias películas en rodaje. Cualquier forma de organicidad depende de la cámara que unifica, pero lo que vemos son fragmentos inconexos, que se revelan artificiales porque vemos como se hace, ya sea porque los actores se preparan para actuar, el director da alguna orden, la cámara está en escena o cualquier trucaje técnico lo demuestra.

No podemos sino pensar que se alcanza una mayor ilusión de naturalidad gracias a su artificialidad confesa. Mientras en otros filmes barrocos el artificio se hace visible por perfección en la imitación, en éste la ilusión de naturalidad opera porque el artificio se niega a ocultarse. No se recurre a rasgos de la escritura moderna como revelar la maquinaria escritural (por ejemplo la presencia de la cámara), pero al tomar como parte de la diégesis el mundo del cine se alcanza la misma inestabilidad estética (gran parte de la historia ocurre en los estudios donde todo el tramoyage está al descubierto). La segunda parte del filme representa el problema del estudio en donde trabajan nuestros personajes para hacer una película sonora. El resultado es un fiasco. Se nos muestran los problemas que supone el uso del aparataje técnico para capturar el sonido para los actores (pierden movilidad y al moverse el sonido se distorsiona). El cuerpo limitado por la palabra queda alegorizado cuando la acrobacia propia del cine silente queda inmovilizada para hablar al aparatoso micrófono. La película es un fracaso en su noche de pre-estreno.

Lo más interesante, por lo menos en términos alegóricos, es la solución que encuentran para salvar la película y, en consecuencia, el estudio. Optan por convertir el drama en un musical. Y deciden que nuestra protagonista preste su melodiosa voz para doblar a la actriz principal. Se decide por un trabajo en donde el cuerpo genera una sobreescritura de la imagen y la palabra, la falsificación del doblaje. Pero ahora la película que desean rescatar va a imitar la vida, vida donde la dinámica musical funciona como naturaleza de base.

\section{Cine moderno}

Existe una fuerte tendencia a pensar que el símbolo se manifiesta en el plano cinematográfico. De acuerdo o no, se sugiere que la imagen siempre carga sobre sí la capacidad de operar simbólicamente. Para Martin (2002), el símbolo cobra vida no por la contraposición de imágenes sino por su valor profundo dado en escenas-planos de acción. Mitry (1990) nos dice que la imagen cinematográfica no ofrece una duplicación de un mundo natural. La potencia simbólica yace en la forma de inscripción, más allá del contenido representado. Y si bien el simbolismo opera sobre la inscripción, el filme como texto oficia de contexto. La forma de la expresión transmuta la forma de contenido lo que recuerda el modo de construcción de una connotación.

Nos interesa estudiar el funcionamiento del símbolo en el cine moderno europeo bajo la idea de que la modernidad cinematográfica tiene vocación simbólica en la medida 
en que, como respuesta al clasicismo, opta por una estética que abraza el misterio. Con esta sugerencia, queremos evocar un cine que no se complace en los intereses de extender lo real de manera directa, que se rehúsa a las codificaciones naturalistas que desean presentar como estrategia una suerte de doble de lo real. No queremos decir que el símbolo siempre se haga presente en las arcas modernas. Pensamos que puede leerse no solo en términos de modo simbólico, como propone Eco (1998), sino bajo el manto hermenéutico que pone en contacto con un inconsciente cultural, y mediante una lectura semántica que depende de la singularidad de cada obra.

Compartimos la idea de que una característica central del cine moderno es su condición de metalenguaje. No solo un lenguaje que habla del lenguaje, sino un lenguaje que al revisarse a sí mismo se desnuda como artificio. Un lenguaje que se hace visible y no puede ser concebido en un sentido instrumental o mecánico. Aragón (2006) presupone un cine moderno a partir de filmes en vía contraria al cine dominante, lo cual define como contracine agresivo.

\section{Pierrot el loco (1965)}

Godard tiene un rol central en la configuración del cine moderno. En Pierrot el loco nos entrega un relato sobre un escape hacia el sur de Francia. Alejándose de París, Ferdindad y Marianne, nuestros protagonistas, huyen por diferentes parajes en un singular romance. Nuestro antihéroe abandona su familia, nuestra antiheroína es perseguida por la mafia con quien estuvo involucrada. Pero, detrás de este movimiento, se teje una antinarración que sobrepone elementos culturales tales como libros, pinturas, comics, guerras, resistencias políticas, etcétera.

Podría pensarse que tras un filme de esta naturaleza se auscultan las relaciones entre hombres y mujeres como liberación de las expectativas sociales. En un marcado anarquismo pareciera oírse un grito libertario condenado al fracaso, como atestiguamos al final del relato. La historia de amor es una farsa y la muerte como anulación la única respuesta. Todo el periplo, que puede ser considerado como un road movie, pareciera estar ceñido a la multiplicación de rasgos culturales. La poética de Godard hace del filme una naturalización de signos volviendo la cultura parte del paisaje. En dicho acto, los personajes se nos ofrecen en calidad de simulacros. No buscan ser la prolongación de una biografía, sino un sabotaje de cualquier elemento que los haga reales. Testimonio de ello son los diálogos (con una marcada poética del absurdo) en los cuales nuestros protagonistas se involucran como si fueran otros. Sus bocas territorializan historias que nos les pertenecen. Y como espectadores tenemos la impresión que están hechos de papel (o de luz), no de carne y hueso.

En este marco quisiéramos explorar dos símbolos concretos: los libros y el baile. Cuando pensamos en el los libros en Pierrot el loco tenemos en mente tanto el hecho 
de que el filme es una adaptación de una novela, como el hecho de que las referencias librescas se multiplican. En múltiples ocasiones nuestro protagonista lee en medio del viaje al sur. Los libros han sido simbolizados como puertas o como ventanas. Se deben abrir y son marcos para mirar un universo posible. Un libro se escribe, pero el libro como escritura hace mundo (como sugiere Derrida). Y en calidad de modo simbólico eso revela la naturaleza del cine moderno en nuestro filme. La dimensión de metalenguaje queda simbolizada en la presencia del libro. Se nos recuerda que lo que vemos es escritura de la realidad, no representación. Y a esa conclusión podemos Ilegar analizando semióticamente el tipo de narración con falsos raccord o mediante el estilema de la hipercontinuidad, como reconociendo las marcas textuales que ofician de ventanas. No hay otro mundo para nuestros protagonistas que ese que atestiguan los libros. Ellos son tanto la extensión de la cultura del trazado como las inscripciones permanentes que hacen en su viaje autárquico.

Basta recordar que todo libro supone, por lo menos en clave etimológica (liber), el acceso a la corteza (a la materia que hace-encubre el árbol). No podemos dejar de pensar que las manos de Ferdinand son prótesis del libro y no viceversa. Esto puede reconocerse en el hecho de que todo el filme está cargado de referencias culturales, como si el mundo fuera el efecto de escritura de las dinámicas librescas, como si no existiese otra realidad que la que nos otorgan las pinturas de Velásquez, el cine de Fuller, los cómics franceses, las guerras televisadas (que se referencian en el filme). El libro es símbolo de la cultura (lo cual ya sabemos) porque, en este filme, violenta la diferencia natural/artificial.

Nos gustaría pensar el baile como un modo de desterritorializar el cuerpo. Estamos en presencia de la artificialidad en el cuerpo de nuestros personajes. Casi siempre bailan o parecen bailar. No nos referimos a que bailen en el marco de una fiesta o en una ocasión social. Solamente que sus movimientos, que parecen rasgar el escenario en que se les ubica, sugieren una movilidad que rompe el aparente orden natural. Culturalmente el baile tiene funciones rituales que anticipan la vida o la muerte (nacimientos y defunciones). Por ello en los cuerpos de Ferdinand y Marianne se oficia una apertura hacia un nuevo comienzo, hacia un nuevo final. Cuando corren escapando, comienzan su distancia del mundo social cuando se persiguen mutuamente, se anticipa una la muerte de ambos.

Este trabajo simbólico tiene un especial momento en una escena del filme en la cual nuestros personajes evocan el cine musical. Si bien no estamos en presencia de un baile completamente coreografiado, los movimientos sugieren una mecánica propia del cine clásico. En este coqueteo, que es al mismo tiempo una batalla entre géneros, nuestros personajes hacen de sus cuerpos un efecto de la cultura de Hollywood. El diálogo, en calidad de canto, es prólogo del debacle. Luego, todo entre ellos conduce al trágico desenlace. Como si la vida, con todo su misterio, no pudiera ser controlada por teoría alguna, como si solo restara (tras la lucha) seguir bailando. 


\section{Deseo de una mañana de verano (1966)}

Esta obra de Michelangelo Antonioni ha sido identificada como una radiografía de la cultura pop. Basada (en calidad de pretexto) en el cuento Las babas del diablo, deviene en un singular trabajo de metalenguaje sobre la imagen. Supone una reflexión sobre cómo la imagen se convierte en símbolo de una generación, lo cual refigura las relaciones con lo real. En dicho marco, tiene lugar una fuerte tensión entre lenguajes que sugiere, finalmente, una suerte de disolución. Frente al tradicional poderío de la palabra, pasamos a su mutismo, a su imperfección. Y la vaguedad visual goza en este caso de la fuerza simbólica que abre un universo capaz de decir sin reducción conceptual.

Del relato pretendemos retener el hecho de que nuestro protagonista es un célebre fotógrafo que, de diversos modos, divaga por la ciudad en búsqueda de nuevas imágenes. En medio de su vagabundeo, retrata el flirteo de una pareja en un parque. Se sugiere que dicho amor es clandestino y su lente oficia de testimonio irruptor. Lo importante es que al revelar las imágenes, en calidad de sombras, de extraña imperfección, en las fotos aparece una confusa silueta (a simple vista) que obsesiona a nuestro protagonista. Oficia, de ahí en adelante, como el más tozudo investigador que desea descubrir un misterio. Y tras la pesquisa se topa con un cadáver. La muerte emerge como centro de la imagen. Tras regresar al parque en búsqueda de los restos, no halla nada. Pareciera que solo el filtro visual tiene la potencia de revelar los misterios que nos rodean.

Revisaremos dos símbolos: la fotografía y el cadáver. Las fotografías cargan la historia de una lucha por la expresividad. Herederas de diferentes modos de evocar lo real, reclaman la capacidad de ser lenguaje. Vemos a nuestro fotógrafo en acción en el parque en calidad de voyeur, al igual que en varias sesiones profesionales, como en una pequeña orgía en su taller privado, en que fotografía a dos jóvenes que buscan la fama. Sumado a ello, el hogar-taller de Thomas está lleno de fotos. Y cuando desea resolver el misterio son tanto objeto de revisión como de ceremonia; las amplía, revisa fragmentos en ellas, las cuelga en la pared, devienen objetos estéticos.

No es difícil reconocer en las fotos, consideradas iconos, la mutación semiótica a símbolos. Literalmente se convierten en objetos-signo que reclaman tanto el trabajo del icono que copia (del índice que sugiere) como del símbolo que supone todo un código cultural. Pero, más allá de ello, las fotos pasan de ser paisaje (como si la realidad deviniera simbólica) a ser literalmente puerta a un misterio. Y si bien podría pensarse que, tras las formas difusas que interesan al protagonista (literalmente indefinidas), luego se disuelve la extrañeza al reconocer un cadáver, nunca sabemos quién es. Particular modo de simbolización de una sociedad que reconoce que su existencia siempre depende del lenguaje como apertura. A ello puede sumarse el interés de la foto por iluminar-desnudar. Invitación casi ceremonial que atrae al símbolo. Invitación a resolver un misterio, siempre busca amplificar. La escena en que nuestro fotógrafo retoza con las dos aspirantes a modeles desnuda nos pone en la pista de la revelación. 
El cadáver como símbolo solo lo conocemos a través de la imagen. Tradicionalmente los restos humanos son objetos de anulación. Se busca ocultarlos. Por ello, la muerte siempre es evocada como misterio. La sepultura hace de la tierra sello ya que, simbólicamente, se asocia el descenso al subsuelo como un tipo de clausura sobre lo que puede ser conocido. Como si dicha dimensión de lo real no pudiese ser objeto de lenguaje conceptual. Pasa por el modo simbólico con nuestro singular muerto. Se convierte en obsesión, pero no puede hallarlo. Si bien intenta hablar sobre el cadáver con algunos de sus allegados, todo se deshace en balbuceos. El cadáver oficia de símbolo de lo desconocido y de testimonio de que el lenguaje verbal se extingue. De algún modo, nuestro muerto sugerido en las penumbras fotográficas es símbolo del símbolo. Revela que la nebulosa de contenido no se agota cuando se apresa. No queda otro camino que la vivencia simbólica. Nuestro protagonista pareciera querer penetrar en la foto, regresa al parque $y$, tras no resolver el misterio, termina viendo un partido de tenis entre un grupo de mimos. Y allí, sin palabras (sin lenguaje conceptual) y sin objetos (no hay raquetas ni pelota, ausencia de cuerpo físico) el símbolo da que vivir.

\section{A modo de cierre}

Alegoría y símbolo operan en cualquier materia expresiva. En el cine se inoculan tanto en la imagen como en el relato en su totalidad. La primera se decanta por poner en obra diversos modos de sabotear los sentidos naturales o de base. La segunda sugiere que el sentido siempre es producido en términos vivenciales, cuando se penetra en un lenguaje que abre un mundo inagotable semánticamente. Ambas figuras pueden circular por cualquier estrato histórico del cine. En el caso del cine barroco, las alegorías revelan el exceso de forma que sabotea la representación al hacerla demasiado perfecta. En el caso del cine moderno, los símbolos siempre muestran que sobrepasan cualquier diccionario. Ofician de apertura a un universo de sentido que obliga a la interpretación más allá de cualquier simple descripción de un mundo que precede a la imagen. Figuras que, en términos retóricos, no ofician como ornamentos, sino como fuerzas poéticas para amplificar los resortes discursivos del séptimo arte.

Carlos Fernando Alvarado Duque es profesor titular del Programa de Comunicación Social y Periodismo de la Universidad de Manizales y miembro del Grupo de Investigaciones de la Comunicación; comunicador social y periodista de la Universidad de Manizales, filósofo de la Universidad de Caldas y especialista en Estética de la Universidad Nacional de Colombia. Es doctor en Filosofía de la Universidad de Antioquia.

cfalvarado@umanizales.edu.co 
Misael Alejandro Peralta Rodríguez es comunicador social y periodista de la Universidad de Manizales y candidato a magíster en Diseño y Creación Interactiva de la Universidad de Caldas. Docente e investigador en áreas de periodismo, comunicación, producción de contenidos y humanidades, de las Universidades de Manizales y Católica de Pereira.

mperalta@umanizales.edu.co

\section{Referencias}

ARAGON, T. Imágenes de la modernidad y la vanguardia en el cine de Jacques Tati. Malaga: Universidad de Malaga, 2006.

BENJAMIN, W. El origen del drama barroco alemán. Madrid: Taurus, 1989.

BEUCHOT, M. Hermenéutica, analogía y símbolo. México: Herder, 2004.

BREA, J.L. Noli me legere. El enfoque retórico y el primado de la alegoría en el arte contemporáneo. Murcia: Cendeac, 2007.

BÜRGER, P. Teoría de la vanguardia. Barcelona: Ediciones Península, 2000.

CALABRESE, O. La era neobarroca. Madrid: Cátedra, 1989.

CASETTI, F. ; DI CHIO, F. Cómo analizar un film. Barcelona: Paidós, 1991.

DE MAN, P. Alegorías de la lectura. Barcelona: Lumen, 1990.

DERRIDA, J. La escritura y la diferencia. Barcelona: Anthropos, 1989.

ECO, U. Semiótica y filosofía del lenguaje. Barcelona: Lumen, 1998.

GONZÁLEZ REQUENA, J. Clásico, manierista, postclásico. Repasando la historia del cine americano. Valladolid: Castilla Ediciones, 2006.

LE GUERN, M. La metáfora y la metonimia. Madrid: Cátedra, 1990.

LOTMAN, I. La semiosfera I. Semiótica de la cultura y el texto. Madrid: Cátedra, 1996.

MARTIN, M. El lenguaje del cine. Barcelona: Gedisa, 2002.

MITRY, J. La semiología en tela de juicio (cine y lenguaje). Madrid: Akal, 1990.

OWENS, C. El impulso alegórico: contribuciones a una teoría de la posmodernidad. En WALLIS, B. (Ed.). Arte después de la modernidad. Nuevos planteamientos en torno a la representación. Madrid: Akal, pp. 203-235, 2001.

PANIKKAR, R. Símbolo y simbolización. La diferencia simbólica: para una lectura intercultural del símbolo. En KERÉNYI, E. et al, Arquetipos y símbolos colectivos. Círculo Eranos I. Barcelona: Paidós, pp. 383-414, 1994.

PEIRCE, C. S. La ciencia de la semiótica. Buenos Aires: Ediciones Nueva Visión, 1965.

TODOROV, T. Teorías del símbolo. Caracas: Monte Ávila Editores, 1991. 